\title{
Review: problem solving treatment after deliberate self harm improves depression, hopelessness, and personal problems
}

\author{
Townsend E, Hawton K, Altman DG, et al. The efficacy of problem-solving treatments after deliberate self-harm: \\ meta-analysis of randomized controlled trials with respect to depression, hopelessness and improvement in problems. \\ Psychol Med 2001 Aug;31:979-88.
}

\section{QUESTION: In people committing deliberate self harm, does problem solving treatment improve mood, hopelessness, and personal problems?}

\section{website extra \\ Additional information can be found on the Evidence-Based Medicine website www.evidence-based medicine.com}

\section{Data sources}

Studies were identified by searching Medline; EMBASE/ Excerpta Medica; PsycLIT; the Cochrane Controlled Trials Register; and the Cochrane Depression, Anxiety, and Neurosis Trials Register; and by hand searching journals.

\section{Study selection}

2 reviewers independently selected studies if they were randomised controlled trials that compared problemsolving treatment with any control intervention for deliberate self harm. Studies were excluded if participants were suicide ideators (without self harm) or if deliberate self harm was an outcome variable in people with depression (without previous self harm).

\section{Data extraction}

2 reviewers independently extracted data on patient and trial characteristics and outcomes (depression, hopelessness, and improvement in problems). Disagreements were resolved by a third reviewer.

\section{Main results}

6 studies met the selection criteria. Sample sizes ranged from 10 to 400 patients (mean 97 patients). Control treatments were usual care (2 studies), individual psychological treatment (1 study), general practitioner care (1 study), standard psychiatric treatment (1 study), and brief problem solving treatment, which was standard aftercare focusing on solving the immediate problem rather than providing skills to improve problem solving ability (1 study). 4 studies reported depression outcomes (3 used the Beck Depression Inventory; 1 used the Hospital Anxiety and Depression Scale) and showed that problem solving treatment was more effective than control treatments for relieving depression ( $\mathrm{p}=0.04$ ) (table). 3 studies assessed hopelessness by using the Hopelessness Scale. The pooled results showed that patients in the problem solving group had less hopelessness than did patients in the control group $(\mathrm{p}=0.002)$ (table). 2 studies showed that more patients in the problem solving group than in the control group had improvement in their problems $(\mathrm{p}=0.004)$ (table).

\section{Conclusion}

In patients committing deliberate self harm, problem solving treatment improves depression, hopelessness, and personal problems.

Problem solving treatment $v$ control treatment for deliberate self harm*

\begin{tabular}{|c|c|c|c|c|}
\hline \multirow[b]{2}{*}{ Outcomes } & \multicolumn{2}{|c|}{ Weighted mean scores } & \multirow{2}{*}{$\begin{array}{l}\text { Standardised } \\
\text { mean difference } \\
(95 \% \mathrm{Cl})\end{array}$} & \\
\hline & PST & Control & & \\
\hline \multirow[t]{2}{*}{ Depression (BDI) } & NA & NA & \multicolumn{2}{|l|}{$0.36(0.11$ to 0.61$)$} \\
\hline & & & \multicolumn{2}{|l|}{$\begin{array}{l}\text { Weighted mean } \\
\text { difference }(\mathrm{Cl})\end{array}$} \\
\hline Hopelessness (HS) & 6.22 & 9.19 & \multicolumn{2}{|l|}{$2.97(1.13$ to 4.81$)$} \\
\hline & \multicolumn{2}{|c|}{ Weighted event rates } & & \\
\hline Outcomes & PST & Control & $\mathrm{RBI}(\mathrm{Cl})$ & NNT (Cl) \\
\hline Improvement in problems & $86 \%$ & $61 \%$ & $40 \%(18$ to 67$)$ & 5 (3 to 8$)$ \\
\hline
\end{tabular}

${ }^{*} \mathrm{BDI}=$ Beck Depression Inventory; $\mathrm{HS}=$ Hopelessness Scale; NA = not available; PST = problem solving treat ment. Other abbreviations defined in glossary; weighted mean scores, weighted event rates, RBI, NNT, and $\mathrm{Cl}$ calculated from data in article using a fixed effects model.
Sources of funding: South East Region NHSE Research and Development

Committee and the former Anglia and Oxford NHSE Research and

Development

Committee.

For correspondence: Professor K Hawton University of Oxford, Oxford, UK.

keith.hawton@

psychiatry.oxford.ac.uk.

Hawton K, Arensman E, Townsend E, et al. Deliberate self-harm: systematic review of efficacy of psychosocial and pharmacological treatments in preventing repetition. BMJ 1998;317:441-7. 